\section{UK must go on promoting and funding science}

SIR - Your Editorial "Blair's failure" (Nature 435,$129 ; 2005$ ) refers to a "declining interest amongst the young in science as a career ${ }^{n}$ and states that the UK government should either abandon its target of raising research and development spending from $1.9 \%$ to $2.5 \%$ by 2014, or explain it. I believe that the UK government must retain this target, as the science and engineering base is vital to future global competitiveness. For example, many wealth-creating, innovative companies will develop from Britain's world-class small high-tech companies.

If the UK government is to achieve its economic and social ambitions, it must maintain a strong, diverse supply of scientists to sustain the research base. The brightest and most creative young people need to be inspired to take up careers in science, engineering and technology. Indeed, the number of full-time undergraduates studying for first degrees in science and related subjects is actually rising. And although the media portrayed the closure of two UK university chemistry departments as a major failure, such decisions are influenced by a range of factors, including student demand and a move to concentrate research into larger departments with higher ratings.

There are difficulties in comparing the statistics from the UK Higher Education Statistics Agency, as a result of changes in the classification of subjects from 2002-2003 onwards. However, between 1997-1998 and 2003-2004, the number of people studying science subjects in degree courses increased by more than $30 \%$, at a time when there was a smaller increase (about 20\%) in numbers studying for first degrees overall. The largest increases over this period have been in the biological (including psychology and agriculture) and computer sciences. The rise in popularity of computer sciences is at least in part attributable to the perception of career opportunities. The increase in the numbers studying medicine and dentistry has been accompanied by a welcome increase in the participation of women.

The picture for engineering, technology and the physical sciences is more complex, with subjects such as civil engineering and chemistry attracting fewer students while others, such as astronomy and aeronautical engineering, become more popular. Overseas students account for an increasing proportion in areas such as electronic and electrical engineering, presenting opportunities to retain the best.

Overall, the proportion of students studying for UK degrees in the sciences increased from $38 \%$ to $41 \%$ between 1997-1998 and 2003-2004, a reality very different from the picture painted in the media. Of course there is no reason for complacency: A-level (17-year-old) entries in mathematics, computer sciences, physics, chemistry and biology averaged a decrease of 7.5\% between 1997-1998 and 2003-2004. The UK government needs to continue to take action to enthuse people about the benefits of science education and the potential offered by careers in science.

Such government measures include 'golden hellos' to new science and mathematics teachers, a science and engineering ambassador scheme (in which some 8,500 young scientists act as role models for school students) and investment, jointly with the Wellcome Trust, in Science Learning Centres.

A recent MORI poll (see www.mori.com/ polls/2004/pdf/ost.pdf) reported that $85 \%$ of people believe science makes a good contribution to society. I challenge the media to reflect the positive view of science and technology held by the majority of people in Britain today.

David A. King

Office of Science and Technology,

1 Victoria Street, London SW1H OET, UK

\section{Universal fungus register offers pattern for zoology}

SIR — The proposal by Andrew Polaszek and colleagues in their Commentary article (Nature 437, 477; 2005) for a universal register for animal names as a requirement of the next edition of the International Code of Zoological Nomendature is very welcome. The authors note that a system was tried out by botanists and approved in principle by the International Botanical Congress in Tokyo in 1993, but was rejected by the subsequent congress in St Louis, Missouri, in 1999 and never implemented.

However, a formal system of registration of names was first proposed by mycologists 50 years ago (G. C. Ainsworth \& R. Ciferri, Taxon 4, 3-6; 1955). Many mycologists were disappointed at the St Louis rejection, and in response, they established MycoBank in 2004 (P. D. Crous et al. Mycol. Res 108, 1236-1238; 2004). Authors can obtain a unique accession number for their new entities through the web from MycoBank.org before publication, much in the way GenBank accession numbers are requested. New descriptions with MycoBanknumbers are already appearing in the fungal literature.

The system is voluntary at present, but it is anticipated that leading journals, now starting to recommend this practice, will make it a requirement for the acceptance of papers with new scientific names in them as it becomes better known - just as they already require GenBank numbers for molecular sequences.

MycoBank, led by the Centraalbureau voor
Schimmelcultures fungal biodiversity centre in Utrecht, is being developed in close collaboration with Index Fungorum, an online database of 380,000 scientific names. MycoBank accession numbers are also being incorporated into the life science identifiers scheme.

MycoBank is sure to evolve and become more honed as use of it increases. It provides a model that zoologists and others interested in bringing increased order into the naming of life on Earth might examine.

David L. Hawksworth

IUBS/IUMS International Committee on

Bionomenclature, Departamento de Biología Vegetal II, Universidad Complutense de Madrid, Plaza Ramón y Cajal, Madrid 28040, Spain

\section{Mapping the complexities of science and politics}

Your Editorial (Nature 436, 152; 2005) related the story of how Nature had to carry out the painstaking task of rounding up and destroying several thousand copies of last November's supplement "China voices II" containing a map ofChina without Taiwan, then reprinting it with no map. You assured readers that " whether Taiwan is an independent country ... is not an issue on which Nature takes a stand".

Science recently made a similar clarification - that it has no policy on the Taiwan question - in a published apology by editorin-chief Donald Kennedy (Science 309, 1677; 2005), following that journal's publication in July of a map of China that included Mongolia but not Hainan and Taiwan.

It is a sad reality that people in some quarters in China might still believe that this omission by two leading science journals represent elements of a concerted move with hidden political motivation, no matter what actions were taken by each journal to claim otherwise.

On the other hand, declaring whether to take a stand on a political issue that has nothing to do with science is a significant political statement in itself, especially when it comes from journals with the stature of Nature and Science.

It is a sad day for science and scientists everywhere when these journals are compelled to explain themselves by making declarations of this kind.

Ying-Hen Hsieh

Department of Applied Mathematics, National Chung Hsing University, Taichung, 402 Taiwan

Contributions to Correspondence may be submitted to corres@nature.com. They should be no longer than $\mathbf{5 0 0}$ words, and ideally shorter. They should be signed by no more than three authors; preferably by one. Published contributions are edited. 